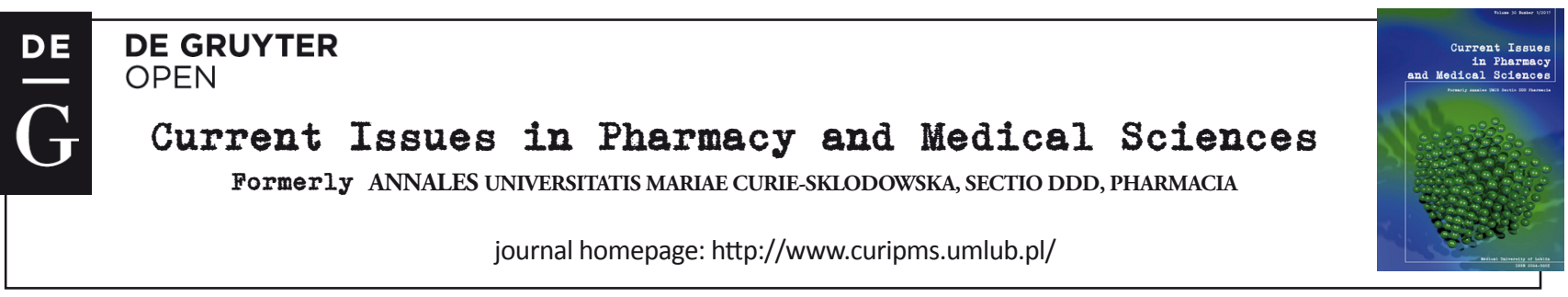

\title{
The use of the Gelot emulsifier in diclofenac sodium semi-solid preparations
}

\author{
Aneta Berner-Strzelczyk ${ }^{1 *}$, Agnieszka JaCH ${ }^{1}$, Justyna Kolodziejska ${ }^{1}$, \\ Michal KolodziejczyK ${ }^{1}$, Malgorzata Godlewska ${ }^{1}$, Magdalena Piechota-Urbanska ${ }^{2}$
}

${ }^{1}$ Department of Drug Form Technology, Medical University of Lodz, Muszynskiego 1, 90-151 Lodz, Poland

2 Department of Applied Pharmacy, Medical University of Lodz, Muszynskiego 1, 90-151 Lodz, Poland

\section{ARTICLE INFO}

Received 14 March 2017

Accepted 09 May 2017

\section{Keywords:}

diclofenac sodium,

emulsifiers,

rheology,

pharmaceutical availability.

\begin{abstract}
In topical formulations, the rheological parameters and pharmaceutical availability of many active agents have been improved by the addition of modern excipients. This translates into increased interest in the topical use of NSAIDs. The aim of this study was to create series of effective oil in water $(\mathrm{O} / \mathrm{W})$ diclofenac sodium cream formulations that differ in the applied fatty phase, utilizing Gelot ${ }^{\mathrm{TM}} 64$ (Gattefossé) (a modern non-ionic emulsifier). In the produced prescriptions, estimation was made of the effect of this on the rheological parameters and the pharmaceutical availability of the diclofenac sodium. Herein, the hydrophilic petrolatum-based cream demonstrated the highest rate of release of the active agent, as well as the best set of beneficial rheological parameters.
\end{abstract}

\section{INTRODUCTION}

Lately, there has been increasing interest in transdermal drug delivery, as the skin is a convenient, easily accessible site of application of therapeutic substances. According to Polish Pharmacopoeia X, semi-solid preparations for external application to skin include: ointments, creams, gels, pastes, poultices and medicated plasters (patches). These products, besides their therapeutic function, also assist in skin care. By delivering drugs to the skin, it is possible to deliver the substance to deeper layers so as to achieve systemic effects $[16,22]$. Transdermal therapy is an excellent alternative to the application of multiple therapeutic agents. Its use eliminates a number of side effects that occur during oral therapy $[3,20]$. It also has advantages over administration of the therapeutic agent in painful injections - which pose the risk of infections and generate hazardous medical waste. Limited skin permeability, resulting from the structural composition of the skin and its barrier function, is a problem in the case of some substances [13,24]. Currently, various techniques are being developed to improve the process of drug permeation, including modification of active ingredient [7] and using surfactants [15] or micro emulsions [11,27], liposomes [5], cyclodextrins [1,4,19], transferosomes [6], oleodendrimers [14] and bacterial cellulose membranes [26].

\footnotetext{
* Corresponding author

e-mail: aneta.berner-strzelczyk@umed.lodz.pl
}

At present, there are many preparations on the market intended for topical application that contain analgesic and anti-inflammatory substances. Semi-solid preparations with NSAIDs for use on the skin were approved by the National Institute for Clinical Excellence (NICE) in 2008, as firstline treatment for osteoarthritis. The FDA has also approved these as safe alternatives to oral NSAIDs [12].

Cordero et al. [8] reported that diclofenac had the highest bioavailability of the NSAIDs assayed by them. It is a derivative of phenylacetic acid, and is used as a relief medication in alleviating moderately severe pain such as dysmenorrhea, neurovascular headache or gout. This preparation tends to accumulate in the synovial fluid. Thus, despite the short half-life, it is effective in the treatment of arthritis. Hence, it is employed as a drug for alleviating symptoms in the long-term treatment of rheumatic diseases such as rheumatoid arthritis, degenerative joint disease and osteoarthrosis.

Diclofenac is also applied topically in treating traumatic inflammation of tendons, ligaments, muscles and joints due to sprains or bruises [12,30]. In ophthalmology, it is prescribed in the treatment of keratitis, conjunctivitis and in the prevention of surgically-induced miosis [2]. Currently, studies are being conducted on formulations that would allow physicians to use diclofenac in dealing with new disease entities in oncology [23], neurology [18] and dermatology [25]. 
Diclofenac is available in a variety of topically applied formulations and newer semi-solid preparations of diclofenac sodium for topical purpose have been in development in the form of light creams and oil in water $(\mathrm{O} / \mathrm{W})$-type emulsions.

As noted in literature, emulsion systems are a promising form of topically applied drugs. They are preferred by patients because they are more easily washed off with water than are ointments, and they leave a less greasy feel. The application on skin is easy, prompting patients to comply with the requirements of the therapy, and significantly influences the effects of the treatment [29].

The objective of the study was to select a suitable fatty phase of the test product, which after the use of a Gattefossé-Gelot ${ }^{\mathrm{TM}} 64$ emulsifier, would ensure the obtaining of an $\mathrm{O} / \mathrm{W}$ cream of best rheological parameters for effective release of the therapeutic agent and for easy application. Gelot ${ }^{\mathrm{TM}} 64$ is a modern, non-ionic emulsifier produced by Gattefossé. It is intended for products applied topically, rectally and intravaginally. Gelot ${ }^{\mathrm{TM}} 64$ is a mixture of glycerol monostearate and PEG-75 stearate. It is a universal O/W non-ionic emulsifier (HLB of 10), and it comes in the form of semisolid pellets of faint odor. It is most frequently used at concentrations of $2-7 \%$ and even up to $20 \%$. Moreover, it is stable over a wide $\mathrm{pH}$ range (3-11) and the $\mathrm{pH}$ of the emulsifier solution in water is 3.4-6.5. The melting point of Gelot ${ }^{\mathrm{TM}} 64$ is $55.5-62.5^{\circ} \mathrm{C}$ [28].

Glycerol monostearate, a component of Gelot ${ }^{\mathrm{TM}} 64$, is a non-ionic emulsifier. It is formed when one hydroxyl group of glycerol is esterified with stearic acid. In the glycerol monostearate molecule, an alkyl chain is lipophilic, whereas non-esterified hydroxyl groups are hydrophilic. The HLB of this emulsifier is 4 and it forms $\mathrm{O} / \mathrm{W}$-type emulsions. It is mainly used as an adjuvant emulsifier [22].

PEG-75 stearate is a fatty acid ester (in this case to stearic acid) and a polyoxyethylene glycol (PEG). Herein, the longer the PEG chain, the greater the hydrophilicity of the emulsifier molecule (the higher the number of PEG, the longer the chain). PEG-75 stearate is used in the formulation of $\mathrm{O} / \mathrm{W}$-type emulsions.

Gelot ${ }^{\mathrm{TM}} 64$ is suitable for the emulsification of formulations for topical application to the skin that are difficult to form as stable emulsions, e.g. preparations for external use with niosomes containing resveratrol [22], sunscreen creams, hair removal creams and hair straightening formulations. Emulsions formed owing to this emulsifier provide creamy texture and perfect distribution upon the skin. What is more, these preparations when distributed on the skin, leave a non-perceptible film that is neither greasy or sticky.

The product is safe and poses no threat to human health.

In our work, the prepared formulations were subjected to complementary physicochemical tests designed for semisolid preparations for cutaneous application. The effects of the applied vehicle on the pharmaceutical availability of the therapeutic agent and the rheological properties of the produced formulations were determined. Then, formulations of the best application properties and the highest release profile were selected.

\section{MATERIALS AND METHODS}

The following were used to prepare the products for this study.

\section{Materials}

Diclofenac sodium - Sigma-Aldrich; white petrolatum - Galenic Laboratory Olsztyn Ltd.; hydrophilic petrolatum - Coel Pharmaceutical Laboratory, Eucerin Plant; white wax - Galfarm Ltd.; liquid paraffin - Amara; olive oil; Gelot ${ }^{\mathrm{TM}} 64$ - Gattefosse SAS; purified water; and a buffer solution of $\mathrm{Na}_{2} \mathrm{HPO}_{4}-\mathrm{C}_{6} \mathrm{H}_{8} \mathrm{O}_{7} \cdot \mathrm{H}_{2} \mathrm{O}(\mathrm{pH} 5.00 \pm 0.05$; $7.00 \pm 0.05)-$ CHEMPUR.

\section{Apparatus}

Cone-plate digital rheometer DV-III - Brookfield, 3.0, with 'Rheocalc for Windows' software; Multifunction Meter CX-505 - Elmetron, with combined electrode EPS-1 - Elmetron Zabrze Extensometer; Apparatus for testing therapeutic agent release from a dosage form DT600 $\mathrm{HH}-$ Erweka; Spectrophotometer Nicolet Evolution 300, version 1.0 - Spectro-Lab; Moisture balance MAC 50 - Precision Engineering Plant Radwag; Automatic mixer Unguator ${ }^{\circledR}$ e/s - Eprus; General electronic laboratory balance B2 - AXIS; Analytical electronic balance AD50 - AXIS; Analytical electronic balance AS 110/C/2 - Precision Engineering Plant Radwag.

\section{Formulation prescription}

The prescription of preparations with diclofenac sodium was worked out. Semi-solid light O/W-type creams, differing in the vehicle fatty phase, were prepared with the use of Gelot ${ }^{\mathrm{TM}} 64$ emulsifier (Gattefossé). The following fatty components were employed in the individual creams:

- white petrolatum (F1),

- white wax (F2),

- white petrolatum and white wax in the ratio 1:1 (F3),

- hydrophilic petrolatum (F4),

- liquid paraffin (F5),

- white wax and olive oil in the ratio 1:1 (F6).

The weight ratio (in $\mathrm{g} / 100 \mathrm{~g}$ of the preparation) of the individual components is shown in Table 1.

Table 1. Composition of the tested formulations (in $\mathrm{g} / 100 \mathrm{~g}$ of preparation)

\begin{tabular}{|l|c|c|c|c|c|c|}
\hline \multicolumn{1}{|c|}{$\begin{array}{c}\text { Formulation } \\
\text { Composition }\end{array}$} & F1 & F2 & F3 & F4 & F5 & F6 \\
\hline Sodium diclofenac (g) & 2.0 & 2.0 & 2.0 & 2.0 & 2.0 & 2.0 \\
\hline Gelot TM64 (g) & 10.0 & 10.0 & 10.0 & 10.0 & 10.0 & 10.0 \\
\hline White petrolatum (g) & 20.0 & - & 10.0 & - & - & - \\
\hline White wax (g) & - & 20.0 & 10.0 & - & - & 10.0 \\
\hline $\begin{array}{l}\text { Hydrophilic (g) } \\
\text { petrolatum (g) }\end{array}$ & - & - & - & 20.0 & - & - \\
\hline Liquid paraffin (g) & - & - & - & - & 20.0 & - \\
\hline Olive oil (g) & - & - & - & - & - & 10.0 \\
\hline Water (g) to & 100.0 & 100.0 & 100.0 & 100.0 & 100.0 & 100.0 \\
\hline
\end{tabular}

Utilizing an Unguator mixer, the suggested creams were produced in accordance with the standard guidelines for these types of formulations. 


\section{Determination of $\mathrm{pH}$}

The measurement of $\mathrm{pH}$ was performed by the potentiometric method - as recommended by the Polish Pharmacopoeia X [9]. The determination was carried out using a $\mathrm{pH}$-meter and a combined electrode, at room temperature.

\section{Tensile test}

The degree of the increase of the area of the cream placed between two plates of an extensometer was determined with the increase of load. The test was conducted at room temperature, and the values of the applied load were matched experimentally.

The results of the measurements enabled an assessment of the dependence $\mathrm{P}=\mathrm{f}(\mathrm{m})$ of the area of the spread creams $\left(\mathrm{cm}^{2}\right)$ on the imposed load $(\mathrm{g})$ [31].

\section{Testing the kinetics of the loss of volatile components}

Determination of the rate of water loss from the prepared creams was performed in the moisture balance, at $32^{\circ} \mathrm{C}$. herein, the determined amount of cream was weighed on an aluminum pan. During a 2.5-hour exposure, readings of the percent weight loss were taken every 15 minutes.

The process of the kinetics of volatile components loss from the tested creams was defined as the percent weight loss $(\%)$ in the function of time $t$. The dependence is illustrated in the graph and described by a correlation equation of the type $y=a x+b$. The area P (c.u.) under the curves presenting the rate of water loss from the tested samples was calculated by the trapezoid method.

\section{Viscosity test}

Viscosity tests were performed at $32^{\circ} \mathrm{C}$, using a digital cone-plate rheometer combined with the "Rheocalc for Windows" software. In this work, the following viscosity parameters were determined: the shear stress at constant shear rates $\left(0.2-2.2 \mathrm{~s}^{-1}\right)$, viscosity and the yield stress. The Casson mathematical model was used to describe flow curves [17].

\section{Determination of pharmaceutical availability of the tested formulations}

The tests of the therapeutic agent release (determination of pharmaceutical availability) from the produced creams to the acceptor fluid were carried out by the chamber method, in accordance with the requirements of the Polish Pharmacopoeia X for transdermal therapeutic systems (TTS) [10].

The weighed amount of the tested cream was placed within an extraction chamber holding a semi-permeable membrane (Visking-Serva). Prior to the determination, the membrane was exposed to purified water for 24 hours. The prepared extraction chamber was inserted into round-bottom beakers of the apparatus for release, and the beakers were filled with purified water. The acceptor fluid was heated to $32^{\circ} \mathrm{C}$. A paddle mixer rotating at $100 \mathrm{rpm}$ was immediately used [10].

The solution samples were collected at determined intervals. The amount of the diclofenac sodium released to the acceptor fluid during a 6 h-exposure was measured in the collected samples by way of utilizing the spectrophotometric method. The absorbance was measured at $\lambda=272 \mathrm{~nm}$, following the earlier determination of the calibration curve presenting the dependence of the absorbance on the concentration of diclofenac sodium.

The course of the calibration curve at the level of significance $\mathrm{p}=0.05$ and a correlation coefficient $\mathrm{r}=0.9999$ was determined by the equation:

$$
\mathrm{A}=0.3175 \cdot \mathrm{C}-0.0014
$$

A - absorbance

$\mathrm{C}$ - concentration of the sodium salt diclofenac $(\mathrm{mg} / 100 \mathrm{ml})$

The mean squared error $(\mathrm{MSE})=0.0001$.

\section{RESULTS}

Preparations with diclofenac sodium of $\mathrm{O} / \mathrm{W}$ type emulsion, with uniform consistency, of white color, odorless and of beneficial properties for application, were obtained. The produced creams were easy to spread, absorbed well and did not leave the skin feeling greasy.

The discussed results are the arithmetic mean of six measurements.

The results of extensometric tests of formulations containing diclofenac sodium were described by the correlation between the increase in the surface area of the tested samples $\mathrm{P}\left(\mathrm{cm}^{2}\right)$ and the applied load $(\mathrm{g})$. Figure 1 presents the extensibility curves of the tested creams. The correlation between the observed increase in the surface area and the applied load is described by the regression equation of the type $y=a x+b$, at the level of significance $p=0.05$. The surface area $\mathrm{P}$ (c.u.) under the curves was calculated using the trapezoid method. The results are shown in Table 2.

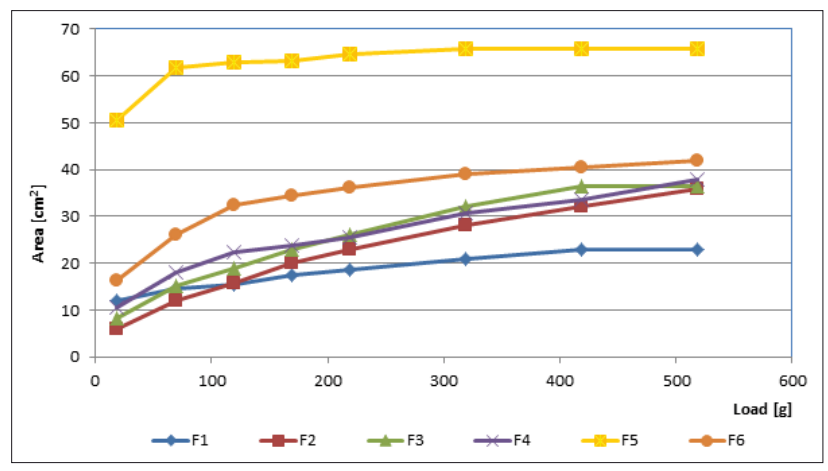

Figure 1. Comparison of the correlation between the observed increase of surface area and the applied load

Table 2. Parameters of the regression equation of the type $y=a x+b$, characterizing the extensibility of the tested formulations

\begin{tabular}{|c|c|c|c|c|c|}
\hline $\begin{array}{c}\text { Tested } \\
\text { formulations }\end{array}$ & $\begin{array}{c}\text { Correlation } \\
\text { coefficient r }\end{array}$ & $\begin{array}{c}\text { Regression } \\
\text { coefficient a }\end{array}$ & $\begin{array}{c}\text { Regression } \\
\text { coefficient b }\end{array}$ & $\begin{array}{c}\text { Area under } \\
\text { the curve } \\
\text { (c.u.) }\end{array}$ & $\begin{array}{c}\text { Area under } \\
\text { the straight } \\
\text { line (c.u.) }\end{array}$ \\
\hline F1 & 0.9713 & 0.0229 & 12.67 & $9,669.8$ & $9,411.9$ \\
\hline F2 & 0.9811 & 0.0580 & 8.07 & $12,143.4$ & $11,827.8$ \\
\hline F3 & 0.9603 & 0.0573 & 11.18 & $13,830.9$ & $13,294.7$ \\
\hline F4 & 0.9160 & 0.0487 & 14.06 & $13,824.6$ & $13,577.5$ \\
\hline F5 & 0.5559 & 0.0203 & 57.87 & $32,430.8$ & $31,666.8$ \\
\hline F6 & 0.8062 & 0.0426 & 23.46 & $17,945.4$ & $17,454.3$ \\
\hline
\end{tabular}


The above results indicate that cream F5 with liquid paraffin demonstrates the highest extensibility $(32,430.8$ c.u.). This cream also reaches the maximum extensibility area very quickly. At the same time, this formulation has a relatively thin consistency, which may result in a flowing away from the application site.

Formulation F6, as the second in turn, has the largest area under the extensibility curve $-17,945.4$ c.u. Although it contains beeswax (which increases the density and hardness of the creams), the addition of olive oil resulted in a good level of spreadability. The use of wax alone as the fatty phase (F2) or wax with white petrolatum (F3) resulted in lower extensibility than that of the F6 combined formulation.

F1 cream, with white petrolatum, is characterized by it distinctly holding the smallest area under the extensibility curve $(9,669.8$ c.u.).

F2, F3 and F4 preparations are characterized by holding comparable extensibility: from $12,143.4$ c.u., to $13,824.6$ c.u. (Fig. 2).

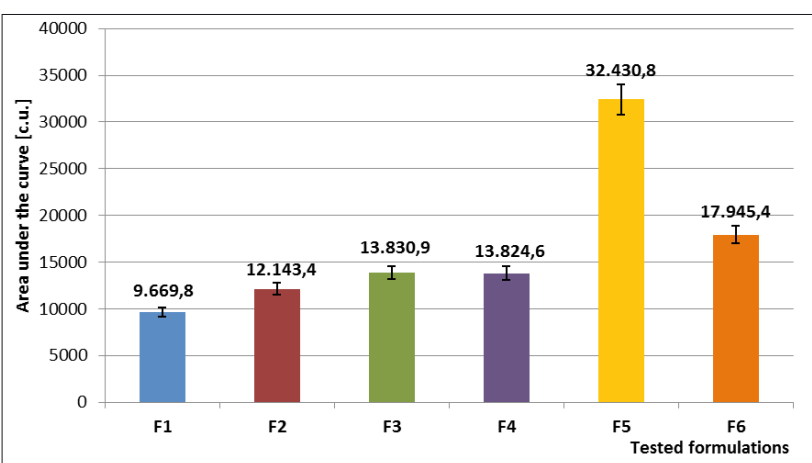

Figure 2. Comparison of the areas under the extensibility curve of the tested formulations

Good spreadability definitely helps patients self-distribute the cream over the administration site, and this determines the therapeutic efficacy due to immediate and complete coverage of the affected site.

Figure 3 reveals the $\mathrm{pH}$ measurement results of the derived diclofenac sodium formulations. The tested creams obtained similar values of $\mathrm{pH}$ : in the range from 7.1 for the F5 sample, to 7.4 for the $\mathrm{F} 3$ sample. This $\mathrm{pH}$ range is considered to be safe for the skin, and such $\mathrm{pH}$ ensures diclofenac sodium stability in the produced cream.

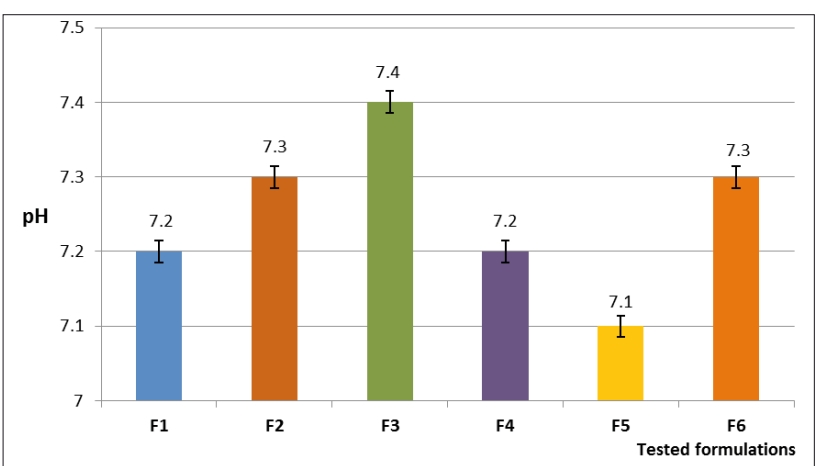

Figure 3. Comparison of $\mathrm{pH}$ values of the produced formulations

The rate of water loss from the demonstrated creams is presented in Figure 4. The course of the dependence of percent loss of volatile components $(\%)$ on the exposure time $\mathrm{t}$ for the tested formulations was characterized by the regression equation of the type $y=a x+b$, at the significance level of $p=0.05$. The trapezoid method was used to calculate the surface area P (c.u.) under the curves. Table 3 shows the parameters of the regression equation.

Table 3. Parameters of regression equation of the type $y=a x+b$, characterizing the rate of water loss from the formulation

\begin{tabular}{|c|c|c|c|c|}
\hline $\begin{array}{c}\text { Tested } \\
\text { formulations }\end{array}$ & $\begin{array}{c}\text { Correlation } \\
\text { coefficient } r\end{array}$ & $\begin{array}{c}\text { Regression } \\
\text { coefficient a }\end{array}$ & $\begin{array}{c}\text { Regression } \\
\text { coefficient b }\end{array}$ & $\begin{array}{c}\text { Area under } \\
\text { the curve (c.u.) }\end{array}$ \\
\hline F1 & 0.9427 & 0.39 & 17.92 & $7,197.00$ \\
\hline F2 & 0.9523 & 0.29 & 17.84 & $5,970.00$ \\
\hline F3 & 0.9537 & 0.32 & 16.37 & $6,089.00$ \\
\hline F4 & 0.9623 & 0.35 & 18.54 & $6,442.00$ \\
\hline F5 & 0.9203 & 0.31 & 26.04 & $7,138.00$ \\
\hline F6 & 0.9295 & 0.30 & 25.00 & $6,829.00$ \\
\hline
\end{tabular}

The process of water loss is accompanied by a proportional increase in structural viscosity (the larger the area under the curve of volatile component loss, the higher the viscosity). Too fast and sudden loss of volatile components during the storage of the creams may result in increased viscosity and reduced spreadability, and, thus, less convenient use of the product, both when squeezed out of the tube and when distributed on the patient's skin. Such a result was obtained for the F1 cream $(7,197.00$ c.u.) with white petrolatum as a fatty phase. This cream also demonstrated the weakest extensibility. The F5 cream with liquid paraffin was characterized by a slightly smaller loss of volatile components $(7,138.00 \mathrm{c.u}$.). This formulation also had the disadvantageous too high extensibility.

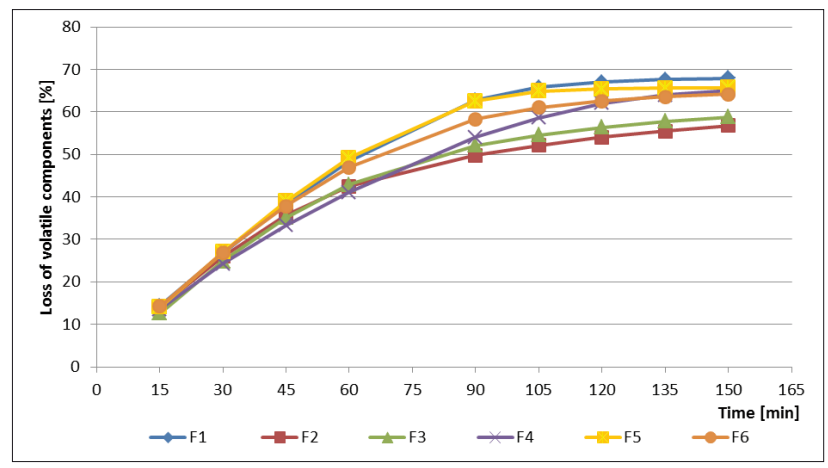

Figure 4. Comparison of the dependence between the rate of water loss and exposure time of the tested formulations

The analysis of water loss from the tested samples during exposure at $32^{\circ} \mathrm{C}$ showed that initially the rate was similar in all creams. However, after 30 minutes, the differences became more pronounced (Fig. 4). After 150 minutes, the least water loss was observed in the F2, F3 and F4 formulations (Fig. 5). Thus, it is possible to predict the highest stability of these creams during storage, and, moreover, to expect at that time, the least change in viscosity in relation to the baseline values. The flow curves of the produced creams were determined on the basis of viscosity measurements. Graphically, they are presented in the form of the dependence between the shear stress and the shear rate of the tested creams (Fig. 6). 


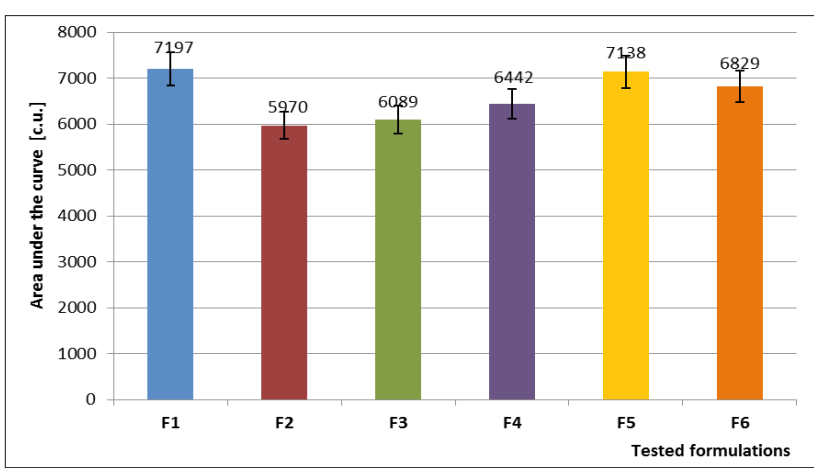

Figure 5. Comparison of the area under the volatile component loss curve

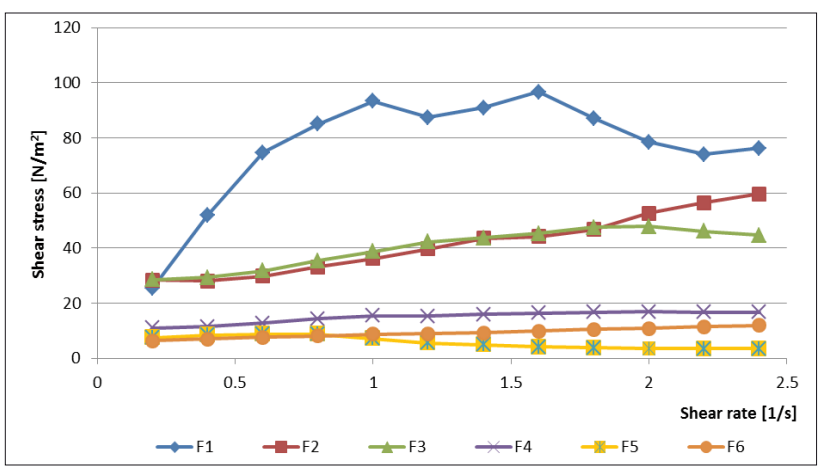

Figure 6. Comparison of flow curves of the tested formulations

The tested formulations are non-Newtonian systems, and their internal structure is destroyed with increasing shear stress. This is manifested by their decreased viscosity. These are plastic systems, and their flow curves do not cross the start of the co-ordinate system. What is more, they have the boundary value of shear stress at that which they begin to flow - the yield stress $\tau_{0}$. The obtained results demonstrate that the F1 cream, produced on a white petrolatum base, is a system diluted with shear. In the F1 cream, with regard to the increase in shear rate, the shear stress increases more slowly than proportionally (Fig. 6). A similar, though definitely much smaller, dependence was observed for the F2 and F3 formulations. However, for the F4 and F6 formulations, a slight progression of shear stress was observed with increasing shear rate.

The flow curve of the F5 cream (produced on the liquid paraffin base) demonstrated a different course. For this preparation, a slight decrease in shear stress was observed with each increase in shear rate. This implies that it is a socalled 'shear thickening' system (Fig. 6).

A graphic illustration of flow curves enables a comparison of the value of the structural viscosity of the tested diclofenac sodium formulations, and the value of their yield stress. The yield stress (plasticity) $\tau_{0}$ was calculated according to the Casson model (Tab. 4).

Table 4. Parameters of Casson model determined at $32^{\circ} \mathrm{C}$

\begin{tabular}{|c|c|c|}
\hline Tested formulations & Plastic viscosity (mPa.s) & Yield stress $\left(\mathrm{N} / \mathrm{m}^{2}\right)$ \\
\hline F1 & $1,262.00$ & 51.9 \\
\hline F2 & $5,437.00$ & 15.1 \\
\hline F3 & $1,994.00$ & 22.4 \\
\hline F4 & 215.50 & 10.9 \\
\hline F5 & 973.80 & 12.1 \\
\hline F6 & 709.70 & 4.5 \\
\hline
\end{tabular}

The highest viscosity $-106,358.00 \mathrm{mPa} \cdot \mathrm{s}$, at a shear rate of $0.81 / \mathrm{s}$, was found in the F1 cream (white petrolatum). Such high viscosity value and (described earlier) lowest spreadability, may disqualify this prescription due to applicative reasons. In contrast, all other creams are characterized by held significantly lower viscosity values (Tab. 5).

Table 5. Viscosity parameters determined at two randomly selected shear rates at $32^{\circ} \mathrm{C}$

\begin{tabular}{|c|c|c|c|c|}
\hline \multirow{2}{*}{$\begin{array}{c}\text { Tested } \\
\text { formulations }\end{array}$} & \multicolumn{2}{|c|}{ Shear rate 0.8 (1/s) } & \multicolumn{2}{c|}{ Shear rate $1.8(1 / \mathrm{s})$} \\
\cline { 2 - 5 } & $\begin{array}{c}\text { Shear stress } \\
\left(\mathrm{N} / \mathrm{m}^{2}\right)\end{array}$ & $\begin{array}{c}\text { Viscosity } \\
(\mathrm{mPa} \cdot \mathrm{s})\end{array}$ & $\begin{array}{c}\text { Shear stress } \\
\left(\mathrm{N} / \mathrm{m}^{2}\right)\end{array}$ & $\begin{array}{c}\text { Viscosity } \\
(\mathrm{mPa} \cdot \mathrm{s})\end{array}$ \\
\hline F1 & 85.10 & $106,358.00$ & 87.10 & $48,375.00$ \\
\hline F2 & 33.20 & $41,499.50$ & 46.72 & $25,954.44$ \\
\hline F3 & 35.39 & $44,233.21$ & 47.51 & $26,396.22$ \\
\hline F4 & 1.30 & $17,892.00$ & 16.70 & $9,277.00$ \\
\hline F5 & 8.75 & $10,934.00$ & 3.78 & $2,098.00$ \\
\hline F6 & 8.15 & $10,189.00$ & 10.50 & $5,854.00$ \\
\hline
\end{tabular}

However, the F5 prescription demonstrates very low values of structural viscosity: $10,934.00 \mathrm{mPa} \cdot \mathrm{s}$, at a shear rate of $0.8 \mathrm{1} / \mathrm{s}$; and $2,098.00 \mathrm{mPa} \cdot \mathrm{s}$, at a shear rate of $1.8 \mathrm{1} / \mathrm{s}$. The held very low structural viscosity values and too high spreadability parameters encourage a rejection of formulation F5 (liquid paraffin). The F6 formulation (beeswax and olive oil) demonstrates similarly low viscosity as the F5 preparation.

The remaining formulations: F2, F3, and F4 are characterized by holding intermediate values of structural viscosity. At a shear rate of $0.8 \mathrm{l} / \mathrm{s}$, they are within the range of 17,892.00-44,233.21 mPa.s (Tab. 5).

All formulations hold yield stress, i.e. after exceeding a certain boundary shear stress, they demonstrate a tendency to flow, while at lower stress, they behave like elastic solid bodies. The highest value of yield stress was demonstrated by the $\mathrm{F} 1 \mathrm{cream}-51.9 \mathrm{~N} / \mathrm{m}^{2}$, and the lowest by the $\mathrm{F} 6$ cream $-4.5 \mathrm{~N} / \mathrm{m}^{2}$ (Fig. 7, Tab. 4).

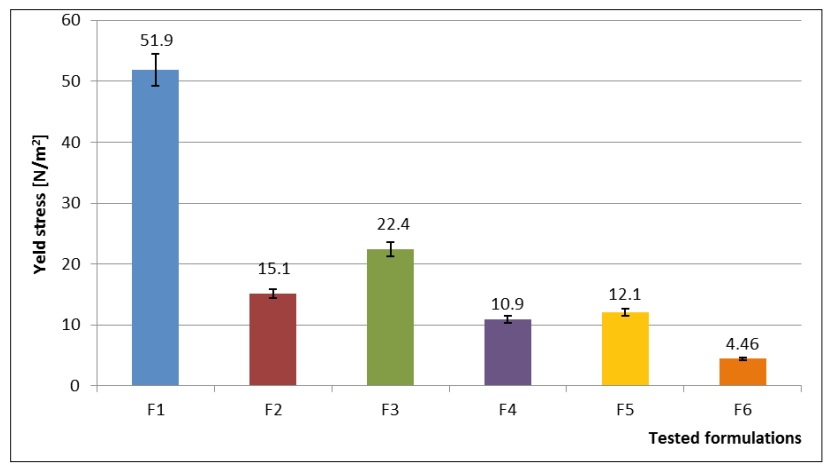

Figure 7. Comparison of the value of yield stress of the tested formulations

There is a correlation between the values of the yield stress of semi-solid preparations and their application properties. The lower the yield stress value, the better the cream is distributed on the skin. In addition, the lower the yield stress value, the easier it is to be squeezed out of a tube container. Such formulations also have greater capacity to restore their structure. A higher value of boundary shear stress indicates a more rigid structure. 
The tested formulations are rheologically unstable thixotropic systems, and they are characterized by holding positive thixotropy. This means that during viscosity tests performed at the same temperature $\left(\mathrm{T}=32^{\circ} \mathrm{C}\right)$ with the same shear rate, the values of shear stress of the ascending flow curve are higher than the values of shear stress of the descending flow curve. This is a type of hysteresis loop (a graphic presentation of ascending and descending flow curves), and is characteristic of systems exhibiting thixotropy. The hysteresis loop test was carried out by gradually increasing the shear rate to a certain maximal value and then decreasing it. Figure 8 is a revelation of the hysteresis loop of one of the prepared formulations. The ascending flow curve was obtained from the shear stress values at the shear rate from $0.20(1 / \mathrm{s})$ to $1.80(1 / \mathrm{s})$. The descending flow curve was obtained from the values of shear stress from 1.80 $(1 / \mathrm{s})$ to $0.20(1 / \mathrm{s})$.

The rate of diclofenac sodium release from the tested formulations to the acceptor fluid was demonstrated as the correlation between the amount of active agent $(\mathrm{mg} / \mathrm{cm} 2)$ and the exposure time (h) (Fig. 9).

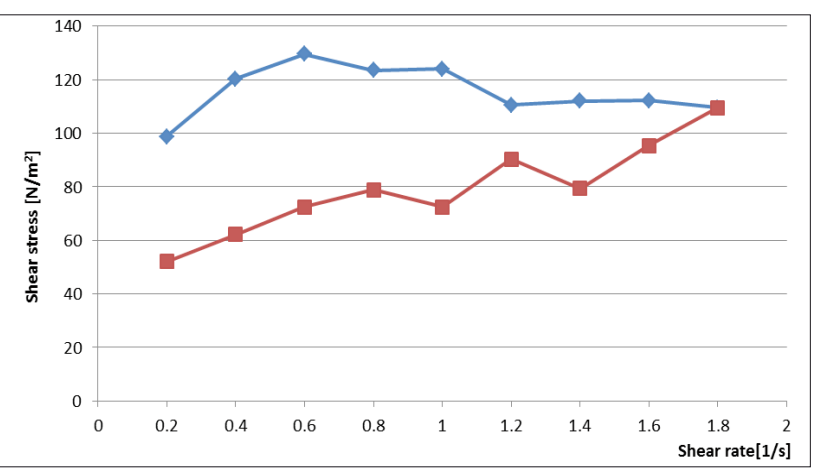

Figure 8. Hysteresis loop of formulation F1

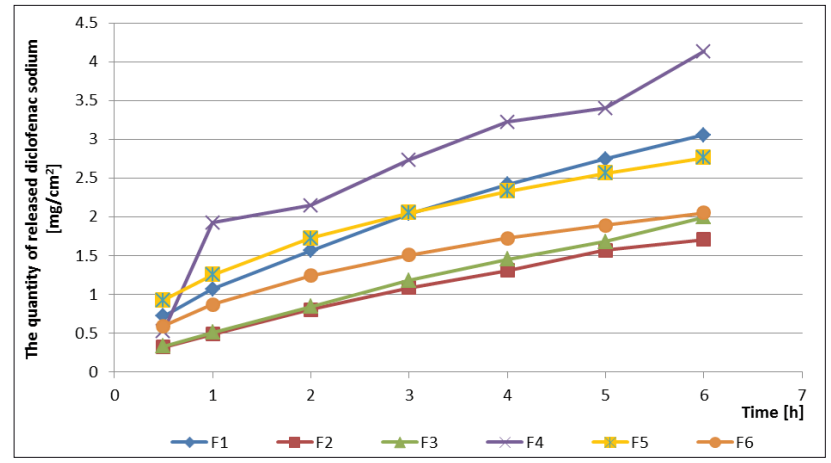

Figure 9. Comparison of the kinetics of diclofenac sodium release from the tested formulations $(\lambda=272 \mathrm{~nm})$

The dependence of the released active agent concentration on the duration of the diffusion process $(\mathrm{Cs}=\mathrm{f}(\mathrm{t}))$ was described by three regression equations at the level of significance $\mathrm{p}=0.05$ :

$$
y=a x+b ; \text { the zero order equation, }
$$

$\ln (100-c)=-k t+\ln a$; the first order equation,

$$
c=K t^{1 / 2} ; \text { the 'square root' equation. }
$$

The correlation coefficients $r$ of the equations describing the rate of the process of diffusion of the active agent from the tested formulations are presented in Table 6 . A determination of the regression equations allowed a definition of the order of the process of diclofenac sodium release. In analyzing the course of regression as a function of time, it was found that the active agent diffusion differed depending on the type of the vehicle. For the F1, F2 and F3 formulations, the release was in accordance with the first order equation. Herein, correlation coefficients $r_{2}$ reached the highest values (close to unity) for these formulations (Tab. 6). However, for the F4, F5 and F6 preparations, correlation coefficients $r_{3}$ reached the highest value (close to unity). Hence, the Diclofenac sodium release from these formulations proceeded according to the square root equation $\mathrm{c}=\mathrm{Kt}^{1 / 2}$.

Table 6. Values of the correlation coefficients of equations describing the rate of diclofenac sodium release from the tested

\begin{tabular}{|c|c|c|c|}
\hline Tested formulations & $\begin{array}{c}\text { Correlation } \\
\text { coefficient } r_{1}\end{array}$ & $\begin{array}{c}\text { Correlation } \\
\text { coefficient } r_{2}\end{array}$ & $\begin{array}{c}\text { Correlation } \\
\text { coefficient } r_{3}\end{array}$ \\
\hline \multicolumn{4}{|c|}{$\lambda=272 \mathrm{~nm}$} \\
\hline $\mathrm{F} 1$ & 0.9928 & 0.9958 & 0.9955 \\
\hline $\mathrm{F} 2$ & 0.9943 & 0.9950 & 0.9831 \\
\hline F3 & 0.9981 & 0.9982 & 0.9744 \\
\hline F4 & 0.9524 & 0.9778 & 0.9798 \\
\hline F5 & 0.9429 & 0.9752 & 0.9970 \\
\hline F6 & 0.9529 & 0.9726 & 0.9989 \\
\hline
\end{tabular}
formulations

Figure 10 compares the amount $\left(\mathrm{mg} / \mathrm{cm}^{2}\right)$ of diclofenac sodium released after the $3^{\text {rd }}$ and $6^{\text {th }}$ hour of pharmaceutical availability testing.

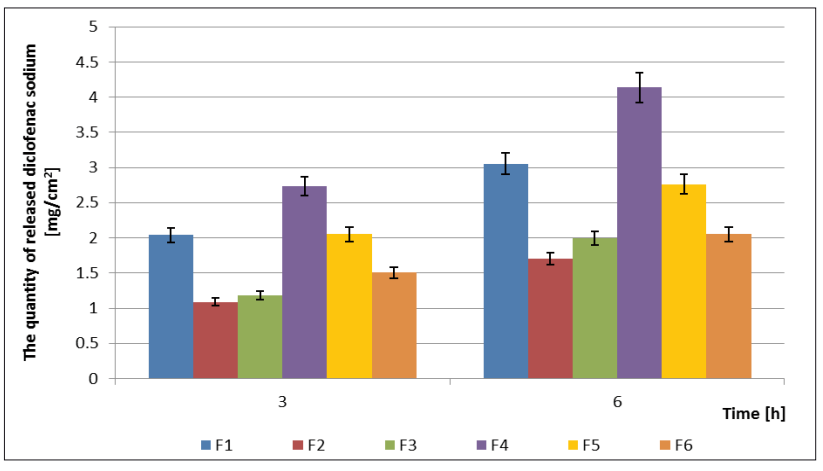

Figure 10. Comparison of the amount of active agent release from the tested formulations after 3 and 6 hours

An analysis of Figure 10 (demonstrating the kinetics of diclofenac sodium release from the produced creams) reveals that the process of diffusion was most effective for the F4 formulation (hydrophilic petrolatum). After a 6-hour exposure, $4,135.1 \mathrm{mg} / \mathrm{cm}^{2}$ of the membrane, or $81.15 \%$ of the total contained diclofenac sodium, was released from the F4 formulation, to the acceptor fluid. At the same time, this formulation is characterized by holding advantageous rheological parameters (the mean value of the area under extensibility curve and the mean value of structural viscosity). Beneficial rheological parameters were also obtained, as mentioned earlier, for the F2 and F3 formulations. However, 
these preparations have a much lower rate of release of the therapeutic agent. The F2 formulation (white wax), after the 6-hour test, reached the lowest rate of diffusion of the therapeutic agent $\left(1,707.5 \mathrm{mg} / \mathrm{cm}^{2}\right.$ of the membrane, or $33.51 \%$ of the total contained diclofenac sodium). After the same time of exposure, in the case of the F3 preparation (beeswax and white petrolatum), the rate of release was $39.2 \%$ of the total amount of diclofenac $\left(1,997.1 \mathrm{mg} / \mathrm{cm}^{2}\right.$ of the membrane).

\section{CONCLUSIONS}

To summarize, the F1, F5 and F6 formulations were rejected due to their held inappropriate rheological properties. However, from among the remaining prescriptions, F2, F3 and F4, all of which held beneficial extensibility and viscosity parameters, the F4 formulation (hydrophilic petrolatum) held distinction, as it demonstrated the highest pharmaceutical availability of diclofenac sodium (81.15\%).

\section{REFERENCES}

1. Alexander A. et al.: Approaches for breaking the barriers of drug permeation through transdermal drug delivery. J. Controlled Release, 164, 26, 2012.

2. Asasutjarit R. et al.: Optimization and evaluation of thermoresponsive diclofenac sodium ophthalmic in situ gel. Int. J. Pharm., $411,128,2011$

3. Cal K.: Nowoczesne metody podawania substancji leczniczych przez skóręw nowych obszarach terapeutycznych na przykładzie transdermalnych systemów terapeutycznych (TTS). Aptekarz Polski, 70/48, 2012.

4. Cal K., Stefanowska J.: Metody zwiększania przenikania substancji leczniczych przez skórę. Farmacja Polska, 66, 514, 2010.

5. Cevc G., Blume G.: New, highly efficient formulation of diclofenac for the topical, transdermal administration in ultradeformable drug carriers. Transferosomes. Biochim. Biophys. Acta, 1514, 191, 2001.

6. Chaudhary H., Kohli K., Kumar V.: Nano-transferosomes as a novel carrier for transdermal delivery. Int. J. Pharm., 454, 367, 2013.

7. Chiarini A., Tartarini A., Fini A.: pH-solubility relationship and partition coefficients for some anti-inflammatory arylaliphatic acids. Arch. Pharm., 317, 268, 1984.

8. Cordero J.A. et al.: A comparative study of the transdermal penetration of a series of nonsteroidal antiinflammatory drugs. J. Pharm. Sci., 86, 503, 1997.

9. Farmakopea Polska X TOM I, (2014). Fizyczne i fizykochemiczne metody badania - Pomiar pH metoda potencjometryczną. Polskie Towarzystwo Farmaceutyczne, p. 110.

10. Farmakopea Polska X TOM I, (2014). Metody badania postaci lekuUwalnianie substancji czynnej z systemów transdermalnych. Polskie Towarzystwo Farmaceutyczne, p. 393.

11. Fouad S.A. et al.: Microemulsion and poloxamer microemulsionbased gel for sustained transdermal delivery of diclofenac epolamine using in-skin drug depot: In vitro/in vivo evaluation. Int. J. Pharm., $45,569,2013$
12. Fuller P., Roth S.: Diclofenac sodium topical solution with dimethyl sulfoxide, a viable alternative to oral nonsteroidal antiinflammatories in osteoarthritis: review of current evidence. J. Multidiscip. Healthc., 4, 223, 2011.

13. Ioele G. et al.: The difficulties for a photolabile drug in topical formulations: The case of diclofenac. Int. J. Pharm., 465, 284, 2014.

14. Kalhapure R.S., Akamanchi K.G.: Oleodendrimers: A novel class of multicephalous heterolipids as chemical penetration enhancers for transdermal drug delivery. Int. J. Pharm., 454, 158, 2013.

15. Lane M.E.: Skin penetration enhancers. Int. J. Pharm. 447, 12, 2013.

16. Łubkowska B., Grobelna B., Maćkiewicz Z.: Przenikanie składników aktywnych przez skórę. Pol. J. Cosmetol., 15, 33, 2012.

17. Milão D. et al.: Hydrophilic gel containing nanocapsules of diclofenac: development, stability study and physico-chemical characterization. Pharmazie, 58, 325, 2003.

18. Mohammadi R., Hirsaee M.A., Amini K.: Improvement of functional recoveryof transected peripheral nerve by means of artery grafts filled with diclofenac. Int. J. Surg., 11, 259, 2013.

19. Mora M.J., Longhi M.R., Granero G.E.: Synthesis and characterization of binary and ternary complexes of diclofenac with a methyl-beta-CD and monoethanolamine and in vitro transdermal evaluation. Eur. J. Med. Chem., 45, 4079, 2010.

20. Mudshinge S.R. et al.: Nanoparticles: emerging carries for drug delivery. Saudi Pharm. J. 19, 129, 2011.

21. Pando D. et al.: Formulation of resveratrol entrapped niosomes for topical use. Colloids and Surfaces B: Biointerfaces, 128, 398, 2015.

22. Pawlik-Gałczyńska A., Owczarek A., Pluta J.: Skóra jako droga podania substancji leczniczych. Część I. Budowa skóry, wchłanianie leków przez skórę. Farmacja Polska, 63, 287, 2007.

23. Sayen S. et al.: A novel copper (II) mononuclear complex with the non-steroidal anti-inflammatory drug diclofenac: Structural characterization and biological activity. J. Inorganic Biochem., 120, 39, 2013.

24. Shahzad Y. et al.: Breaching the skin barrier through temperature modulations. J. Control Release, 202, 1, 2015.

25. Sharquie K.E. et al.: Treatment of pityriasis versicolor using $1 \%$ diclofenac gel and clotrimazole cream (comparative therapeutic study). J. Saudi Soc. Dermatol. Dermatol. Surg., 15, 19, 2011.

26. Silva N.H.C.S. et al.: Bacterial cellulose membranes as transdermal delivery systems for diclofenac: In vitro dissolution and permeation studies. Carbohydrate Polymers, 106, 264, 2014.

27. Sintov A.C., Botner S.: Transdermal drug delivery using microemulsion and aqueous systems: influence of skin storage conditions on the in vitro permeability of diclofenac from aqueous vehicle systems. Int. J. Pharm., 311, 55, 2006.

28. Technical data sheet-Gelot 64 ; http://www.gattefosse.com/

29. Wadhawa J., Nair A., Kumira R.: Emulsion forming drug delivery system for lipophilic drugs. Acta Pol. Pharm., 69, 179, 2012.

30. Zacher J. et al.: Topical diclofenac and its role in pain and inflammation: an evidence-based review. Curr. Med. Res. Opin., 24, 925, 2008.

31. Zgoda M.M., Kołodziejska J., Godlewska M. (2008). Metody badania wybranych środków farmaceutycznych i kosmetyków. Wydawnictwo Kwieciński p. 8. 